\title{
Determinants of Weight Status for the Residents of the Northwest Arctic Borough of Alaska
}

\author{
Jeanne A. Lewis ${ }^{1}$ and Anshul Pandya ${ }^{1}$ \\ ${ }^{1}$ University of Alaska Fairbanks, Fairbanks, AK, USA
}

\section{ABSTRACT}

While the consumption of a market-based diet is increasing, subsistence food still forms a part of caloric intake for Northwest Arctic Borough of Alaska residents. The purpose of this study was to assess the influence of consumption of a market-based diet compared to a subsistence diet on the body mass index (BMI) of the people living in this region. For this, 82 adult participants were recruited, and their weight and height were measured to calculate the Body Mass Index (BMI). The participants were asked to complete a questionnaire that included questions about their family background, lifestyle, physical fitness and dietary patterns. Linear regression models were used to examine BMI's association with variables of diet and physical activity, followed by correlational analysis between BMI and these variables. No significant correlation was identified between BMI and how often people ate a subsistence-based diet. A strong positive correlation was found between BMI and how often people eat food prepared in a restaurant or ate fast food and junk food. A strong negative correlation was found between BMI and frequency of exercise by the participants. Physical activity and consumption of a western diet rather than a subsistence diet are more significant determinants of BMI among Northwest Arctic Borough of Alaska residents. These results can be used as a baseline for further studies linking diet and health outcomes among this region's residents.

\section{Introduction}

For the people living in rural Alaska, a diet obtained through subsistence activity is increasingly being replaced by a typical western diet containing processed meat, rich in sugars, fat, and salt (1). There is also a decrease in physical activity due to an increased reliance on motorized transportation over the decades (2). These factors have caused an increase in the rates of being overweight and obese among the residents of the arctic region (3). A report from the World Health Organization (WHO) concluded that overweight and obesity represented a growing threat to populations' health across the globe (4). It is well known that being overweight or obese contributes substantially to the burden of chronic health conditions like cardiovascular diseases and type II diabetes (5). As such, obesity may be causing an increase in the risk of developing such diseases and contributing to public health problems in the region.

Due to the lack of roads in rural Alaska, transporting cost is high, making food items costly to purchase (6). Additionally, there is still a cultural reliance on traditional subsistence activities to obtain sources of food. Therefore, subsistence derived food sources form a higher proportion of caloric intake among rural Alaskan (7). Subsistence activity derived foods are generally considered healthier than marked purchased food $(1,8)$. Traditional foods of the arctic people contain more nutrients, less carbohydrate and fat and more protein than store-bought food $(9,10)$. Despite this, the consumption of a so-called "western diet" is increasing rapidly $(7,9,11)$. People of Northwest Arctic Alaska consume market bought foods during their visits out of the region and in their home communities. All these factors can increase the rates of obesity among the residents of this region, similar to that seen in other areas around the Arctic $(12,13)$. This raises the question of an association between individuals' weight status with the type of diet they consume. The purpose of this study is two-fold. Firstly, it is intended to find the prevalence of obesity among Northwest Arctic Borough residents. Secondly, it is designed to identify the correlation between subsistence dietary intake versus market bought western diet and BMI among Northwest Arctic Borough residents. 


\section{Methods and Materials}

Study population: For this study, 82 participants were included. All study participants were the residents of the Northwest Arctic Borough of Alaska for the past year and did not leave the borough for more than two months at a stretch during this time. The determination of sample size was based on the Northwest Arctic Borough ( 8000) and a confidence level of $95 \%$. Participation in the study was voluntary. Enrollment was open to all persons between the ages of 19 and 89 years, able to give informed consent, not pregnant and able to stand on their feet. Signed informed consent was obtained from each participant before their involvement in the study. The study protocols were reviewed and approved by the Institutional Review Board (IRB) of the University of Alaska Fairbanks.

Data Collection: The study participants completed a self and interviewer-administered questionnaire, which had questions on physical fitness and diet. The questionnaire included both fixed multiple-choice and open-ended questions. The accuracy of responses depended on the memory and perceptions of the participants to the questionnaire. This was followed by taking the body measurements of height and weight of participants to calculate their BMI. Weight was measured using digital weight scales (Taylor Precision Products, Oak Brook, IL). Height was measured using a mechanical stadiometer (Detco, Webb City, MO). Weight measurements were taken in light clothing without shoes. Height was measured in centimeters and converted to meters $(\mathrm{m})$, whereas weight was measured and recorded in kilograms $(\mathrm{kg})$. BMI was calculated as weight $(\mathrm{kg})$ divided by height squared $(\mathrm{m})^{2}$.

Statistical analysis: The participants' responses to the fixed and multiple-choice questions in the questionnaire were coded numerically for statistical analysis. The Linear regression was used to test the association between the BMI of the participants and the variables of diet and physical activity individually. The diet variables included servings of subsistence food consumed during each meal, frequency of eating subsistence food, frequency of eating food from a restaurant, and frequency of eating fast food and junk food. The variables of physical activity included were frequency of exercise and the participants' perceived current physical fitness. All the analyses were carried out using GraphPad Prism 6.00 software (GraphPad, San Diego, CA). The relationship between BMI and a variable was deemed to be significant at $p<0.05$. The result of the linear regression analysis is indicated by $\mathrm{r}^{2}$ value (coefficient of determination) and indicated as $\mathrm{r}^{2}, \mathrm{~F}$ value $(\mathrm{F})$, degrees of freedom (numerator, denominator; in parentheses separated by a comma next to $\mathrm{F}$ ), and significance level $(p)$. e.g. $\left[\mathrm{r}^{2}=0.00, \mathrm{~F}(0,00)=0.00, p<0.05\right]$. All the values such as age and BMI are expressed as mean + - standard deviation. Differences between these values were measured using a two-tailed unpaired $t$-test. The weight status is reported as the number of participants and percentages (\%).

\section{Results}

\section{Age and BMI of study participants:}

Of the 82 individuals who participated in the study, 43 were male and 39 were female. The study participants were asked to report their race and ethnicity voluntarily. Of the 82 study participants, 57 individuals reported that they were Alaska native descendants or had mixed racial backgrounds. 17 participants reported their race as Caucasian while the remaining 8 belonged to other races, including Hispanics / Latinos and Asians.

The mean age of all the participants in the study was $38.3+/-15.0$ years. The female participants had a mean age of $42.2+/-15.5$ years, while males who participated in the study had a mean age of $34.8+/-14.0$ years. There we no significant difference between the ages of men and women who participated in the study $(p>0.05)$. The mean BMI of all the participants was $28.6+/-6.53 \mathrm{~kg} / \mathrm{m}^{2}$. The female participants had a mean BMI of $29.6+/-7.35 \mathrm{~kg} / \mathrm{m}^{2}$, whereas males who participated in the study had a mean BMI of $27.6+/-5.6 \mathrm{~kg} / \mathrm{m}^{2}$. There was no significant difference between the measured BMI of men and women participants $(p>0.05)$.

The BMI of all the participants was divided into 4 categories as normal weight (BMI - 18.5 to 24.9), overweight (BMI - 25 to 29.9), obese (BMI - 30 to 39.9) and severely obese (BMI > 40). Out of the 82 individuals included in the study, $6(7.3 \%)$ were identified as severely obese (BMI $\left.>40 \mathrm{~kg} / \mathrm{m}^{2}\right)$. A further $23(28 \%)$ individuals were obese (BMI 
- 30 to $39.9 \mathrm{~kg} / \mathrm{m}^{2}$ ). 24 (29.3\%) individuals were overweight (BMI - 25 to $29.9 \mathrm{~kg} / \mathrm{m}^{2}$ ), while only 29 (35.4\%) of individuals has a normal weight (BMI - 18.5 to $\left.24.9 \mathrm{~kg} / \mathrm{m}^{2}\right)$ with none being underweight $\left(\mathrm{BMI}<18.5 \mathrm{~kg} / \mathrm{m}^{2}\right)(\mathrm{Figure}$. $1)$.

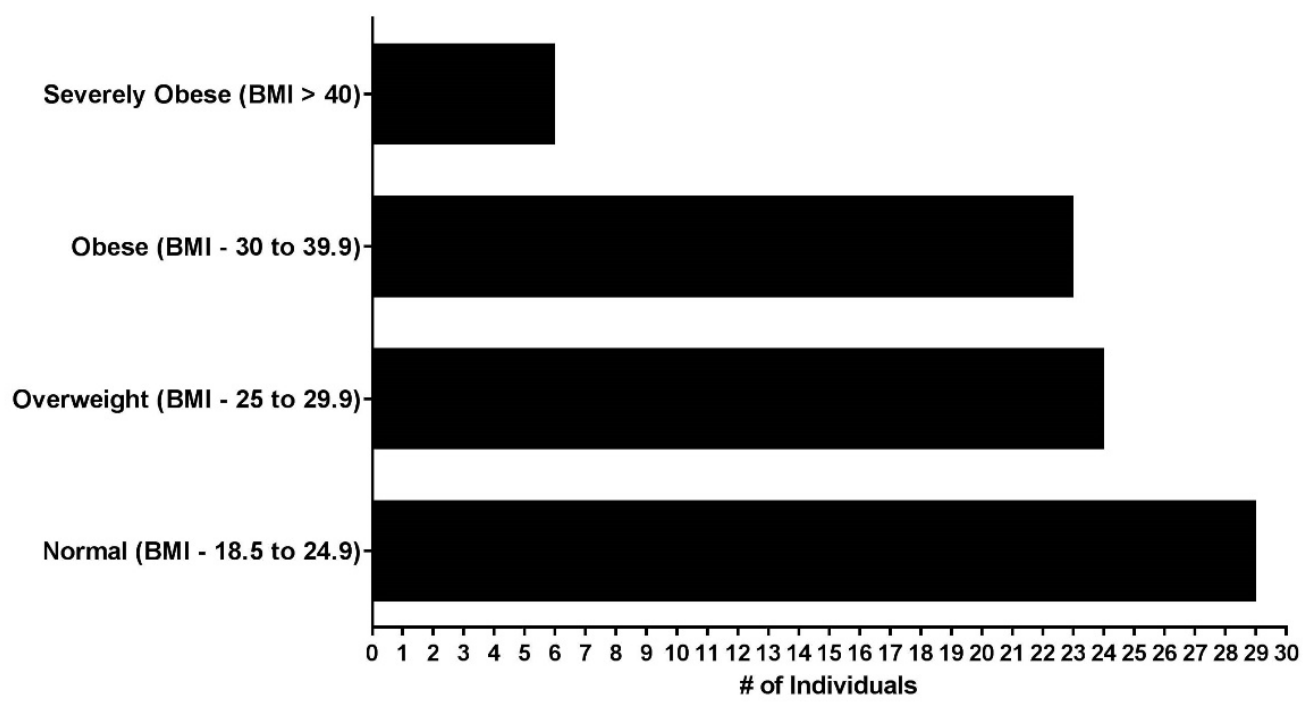

Figure 1: BMI distribution of the study participants, which reflects their weight status.

\section{Relationship between BMI, diet and physical activity:}

The summary of the results is presented in Table .1, where the significance values $(p)$ and the coefficient of determination $\left(\mathrm{r}^{2}\right)$ values are derived from the linear regression analysis. A higher $\mathrm{r}^{2}$ value obtained through this analysis indicates a more significant influence of the variable on BMI. The effect of the age of the participants on BMI was analyzed first. Age did not influence the BMI of the participants. While BMI showed a small increase with participants' age, this relation was not significant $(p>0.05)$.

Table 1: Relationship between different variables and the BMI of study participants identified through linear regression.

\begin{tabular}{|c|c|c|}
\hline Variables & Significance $(p)$ & Coefficient of determination $\left(\mathrm{r}^{2}\right)$ \\
\hline Age & 0.17 & 0.022 \\
\hline Frequency of eating subsistence food & 0.94 & 0.0034 \\
\hline Servings of subsistence food eaten in one meal & 0.60 & 0.31 \\
\hline Frequency of eating food from a restaurant & $<0.0001$ & 0.17 \\
\hline Frequency of eating fast food/junk food & 0.0001 & 0.42 \\
\hline Frequency of exercising & $<0.0001$ & 0.22 \\
\hline
\end{tabular}


Participants were asked to report how often (frequency) they ate subsistence food and the number of servings (quantity) of subsistence food they consumed during each meal. Neither the quantity nor frequency of consumption of subsistence food reported by the participants had any significant effect on BMI ( $p>0.05)$ (Figure. 2).

A.

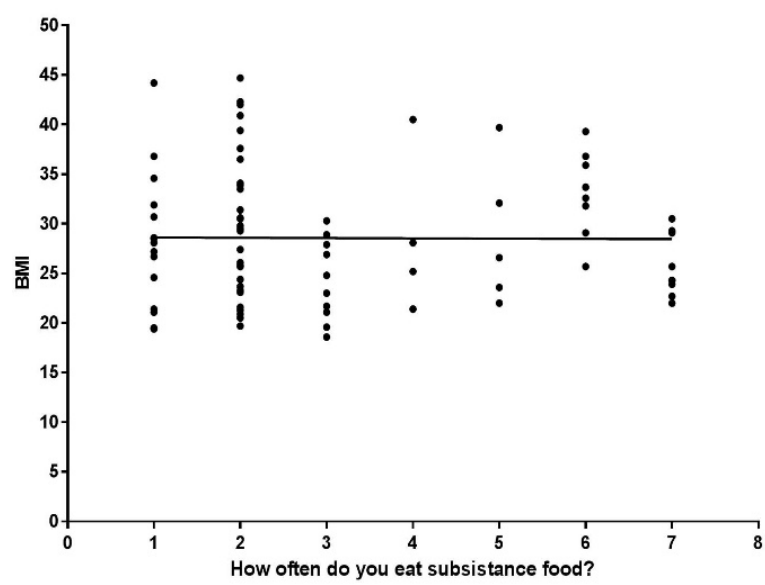

B.

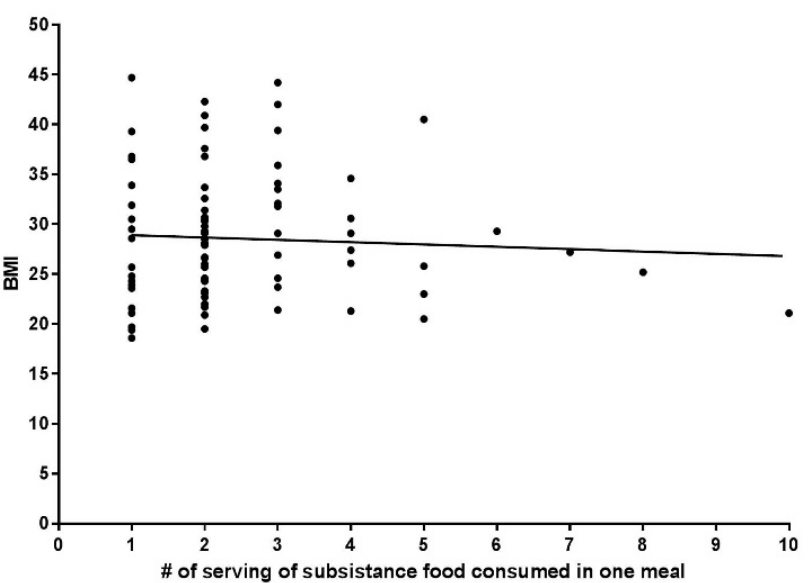

Figure 2: The relationship between BMI and consumption of subsistence food among the study participants. A. Relationship between BMI and frequency of eating subsistence food $\left[\mathrm{r}^{2}=0.000069, \mathrm{~F}(1,80)=0.005591, p=0.94\right]$. B. Relationship between BMI and quantity of subsistence food consumed during one meal $\left[\mathrm{r}^{2}=0.003429, \mathrm{~F}(1,80)=0.2752\right.$, $p=0.60]$.

The questionnaire also asked the participants to report how often they eat food prepared in a restaurant. Individuals who consumed restaurant-prepared food generally had a higher BMI (Figure. 3. A). There was a direct and significant correlation between how often individuals eat food from a restaurant and BMI $\left[\mathrm{r}^{2}=0.31, \mathrm{~F}(1,80)=36.5, p<.0001\right]$. Similarly, individuals who reported eating fast food and junk food more often had a higher BMI (Figure. 3. B). The frequency of eating fast food and junk food was positively correlated to the BMI $\left[\mathrm{r}^{2}=0.17, \mathrm{~F}(1,80)=16.8, p=0.0001\right]$.

A.

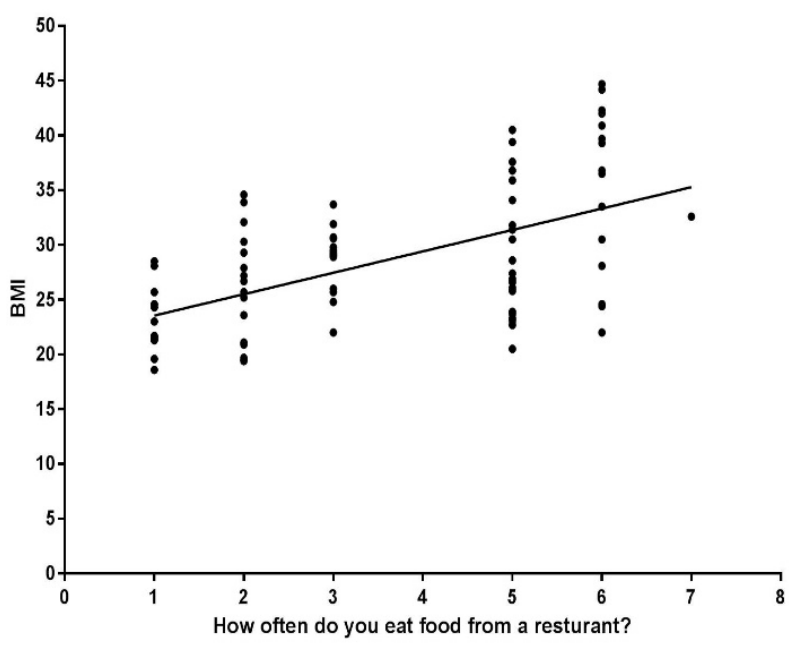

B.

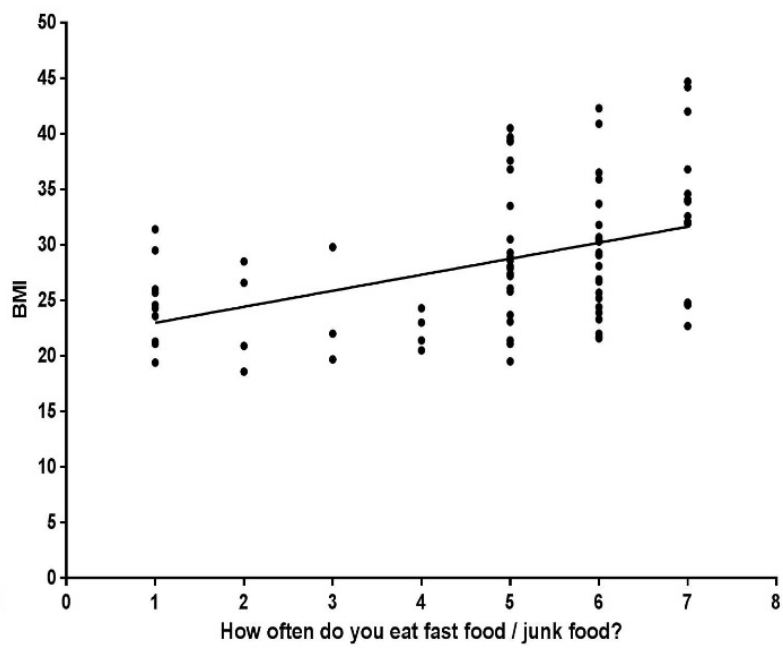


Figure 3: The relationship between BMI and consumption of market bought food among the study participants. A. Relationship between BMI and frequency of eating food prepared in a restaurant $\left[\mathrm{r}^{2}=0.31, \mathrm{~F}(1,80)=36.5, p<.0001\right]$. $\mathrm{B}$. Relationship between BMI and frequency of eating fast food as well as junk food $\left[\mathrm{r}^{2}=0.17, \mathrm{~F}(1,80)=16.8, p=.0001\right]$.

The questionnaire included two crucial questions on physical activity. The first question asked the study participants to report their present physical fitness level as they perceived it to be. They were to choose from a number on a scale of 1 to 10, where a choice 1 corresponded to worst and 10 corresponded to the best perceived physical fitness. The other question asked to report the number of times each week participants indulged in physical activity for 20 minutes or more, including working out in a gymnasium, jogging, running and walking. A strong relationship was identified between participant's perceived present fitness levels and BMI (Figure. 4. A). Higher the BMI worse was the reported feeling of current fitness $\left[\mathrm{r}^{2}=0.22, \mathrm{~F}(1,80)=22.6, p<.0001\right]$. Similarly, a strong relationship was identified between BMI and how often a participant exercised (Figure. 4. B). The more a participant indulged in physical activity lesser was their BMI $\left[\mathrm{r}^{2}=0.42, \mathrm{~F}(1,80)=58.9, p<.0001\right]$.

A.

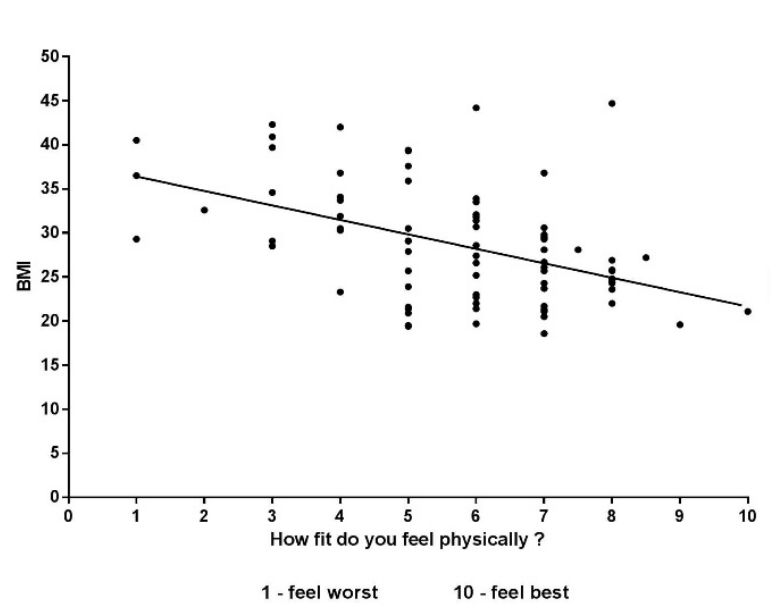

B.

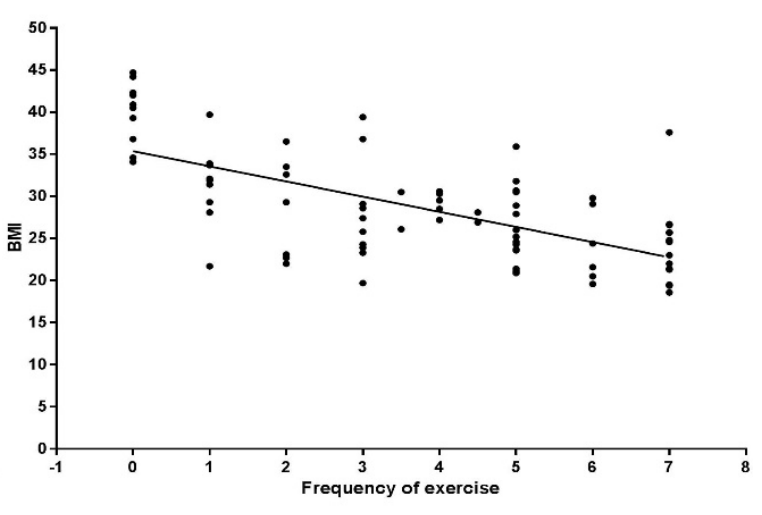

Figure 4: The Relationship between BMI and physical activity among the study participants. Data was analyzed by linear regression followed by correlation analysis. A. Relationship between BMI and perceived current physical fitness $\left[\mathrm{r}^{2}=0.22, \mathrm{~F}(1,80)=22.6, p<.0001\right]$. B. Correlation between BMI and frequency of exercising among the participants $\left[\mathrm{r}^{2}=0.42, \mathrm{~F}(1,80)=58.9, p<.0001\right]$.

\section{Discussion:}

Recent census data of 2010 indicates that the population of Northwest Arctic Borough of Alaska was 7,523; therefore, 82 individuals represent a sample size of about $1.08 \%$ of the borough population (14). The sample of the population included in this study was reflective of the demographic structure of the Northwest Arctic Borough (14). Results show no significant difference between and BMI of men and women included in the study. While men had a slightly higher BMI than women, the difference was not significant. This is reflective of the weight status observed by WHO worldwide (15). The distribution of BMI, which reflects weight status, was similar to a study that reported adults' body weight status in the United States in the year 1997-98 (16).

The results of linear regression were obtained by comparing BMI with the study participants' coded responses to the questionnaire. The responses were based on the perception and memory of participants about the questions they were asked. Therefore, this could influence the results that were obtained. This study's principal focuses was to evaluate the influence of consumption of a market-based diet compared to a subsistence diet on the body mass index of the people living in the Northwest Arctic Borough of Alaska. Therefore the question on dietary patterns and food 
choices of the participants formed the crux of the questionnaire. For this study, subsistence food was defined as meat, fish, seal, birds, fruits, berries, roots, greens and vegetables that have not been purchased commercially from a grocery store (17). The study questionnaire asked the participants to report the quantity and frequency of subsistence food consumption, neither of which had any effect on BMI. A previous study has reported that people of the Northwest Arctic who consumed more subsistence protein more often than the residents of the Chukotka region of Russia were heavier (18). While subsistence food is generally considered healthier, it is possible to be overweight or obese with higher subsistence food consumption.

Food prepared in a restaurant and fast food and junk food was considered as market bought western food in this study, all of which were positively correlated to the BMI. This is not surprising because food prepared in a restaurant; junk food like chips and cookies are all linked to higher BMI $(19,20)$. Fast food and junk food are energydense; however, they offer very few nutrients that the body needs (21). Apart from diet, the strongest correlation in this study was identified between physical activity and BMI. Generally, participants who indulged in more exercise had a lower BMI. This has been consistently observed by many other studies for a long time $(22,23)$. Physical activity combined with avoiding fast food/junk food and food from a restaurant is correlated to lower BMI among Northwest Arctic Alaska residents.

\section{Conclusion:}

As seen from the results of this study, where the influence of different diets was compared, physical activity and consumption of western diet rather than a subsistence diet are bigger determinants of BMI in Northwest Arctic Alaska residents. These results can be used as a baseline for further studies linking diet and health outcomes among the region's residents. Studies like these can be used to devise better public policy regarding food sold in the market across the region. Promote healthy eating and regular exercise will improve the health outcomes among residents of this region.

\section{Acknowledgements:}

This study was funded by a grant to Jeanne Lewis from the Undergraduate Research \& Scholarly Activity (URSA) office of the University of Alaska Fairbanks (UAF). The views expressed are those of the authors and do not constitute URSA's views or that of UAF. We thank all participants who volunteered to participate in this study. I would like to thank my advisor Dr. Anshul Pandya for helping me with this project.

\section{Conflict of interest and funding:}

The authors declare that they have no conflict of interests.

\section{References:}

1. JS Johnson, ED Nobmann, E Asay, AP Lanier. Dietary intake of Alaska Native people in two regions and implications for health: the Alaska Native Dietary and Subsistence Food Assessment Project. Int J Circumpolar Health. 2009; 68(2): 109-22.

2. D Redwood, MC Schumacher, AP Lanier, ED Ferucci, E Asay, LJ Helzer et al. Physical activity patterns of American Indian and Alaskan Native people living in Alaska and the Southwestern United States. Am J Health Promot. 2009; 23(6): 388-95. 
3. N Zienczuk, TK Young, ZR Cao, GM Egeland. Dietary correlates of an at-risk BMI among Inuit adults in the Canadian high arctic: cross-sectional international polar year Inuit health survey, 2007-2008. Nutr J. 2012; 11: 73 .

4. WH Organization. Obesity: preventing and managing the global epidemic. Report of a WHO consultation. World Health Organ Tech Rep Ser. 2000; 894: i-xii, 1-253.

5. A Must, J Spadano, EH Coakley, AE Field, G Colditz, WH Dietz. The disease burden associated with overweight and obesity. JAMA. 1999; 282(16): 1523-9.

6. OP Smith, G Levasseur. Impacts of climate change on transportation infrastructure in Alaska. The Potential Impacts of Climate Change on Transportation. 2002: 151.

7. ED Nobmann, R Ponce, C Mattil, R Devereux, B Dyke, SO Ebbesson et al. Dietary intakes vary with age among Eskimo adults of Northwest Alaska in the GOCADAN study, 2000-2003. J Nutr. 2005; 135(4): 856-62.

8. HV Kuhnlein, O Receveur, R Soueida, GM Egeland. Arctic indigenous peoples experience the nutrition transition with changing dietary patterns and obesity. J Nutr. 2004; 134(6): 1447-53.

9. A Bersamin, BR Luick, IB King, JS Stern, S Zidenberg-Cherr. Westernizing diets influence fat intake, red blood cell fatty acid composition, and health in remote Alaskan Native communities in the center for Alaska Native health study. J Am Diet Assoc. 2008; 108(2): 266-73.

10. HV Kuhnlein, O Receveur. Local cultural animal food contributes high levels of nutrients for Arctic Canadian Indigenous adults and children. J Nutr. 2007; 137(4): 1110-4.

11. PA Loring, SC Gerlach. Food, culture, and human health in Alaska: an integrative health approach to food security. Environmental Science \& Policy. 2009; 12(4): 466-478.

12. T Galloway, ML Chateau-Degat, GM Egeland, TK Young. Does sitting height ratio affect estimates of obesity prevalence among Canadian Inuit? Results from the 2007-2008 Inuit Health Survey. Am J Hum Biol. 2011; 23(5): 655-63.

13. N Petrenya, M Brustad, L Dobrodeeva, F Bichkaeva, G Lutfalieva, M Cooper et al. obesity and obesityassociated cardiometabolic risk factors in indigenous Nenets women from the rural Nenets Autonomous Area and Russian women from Arkhangelsk city. Int J Circumpolar Health. 2014; 73: 23859.

14. U States. Census Bureau. State \& County QuickFacts: Northwest Arctic Borough, Alaska. 2010; Available from: http://quickfacts.census.gov/qfd/states/02/02188.html. (accessed on - 12/4/2014).

15. WHO. Obesity: Situation and trends. 2008; Available from:

http://www.who.int/gho/ncd/risk_factors/obesity_text/en/. (accessed on - 12/2/14).

16. CA Schoenborn, PF Adams, PM Barnes. Body weight status of adults: United States, 1997-98. Adv Data. 2002; (330): 1-15. 
17. DG Redwood, ED Ferucci, MC Schumacher, JS Johnson, AP Lanier, LJ Helzer et al. Traditional foods and physical activity patterns and associations with cultural factors in a diverse Alaska Native population. Int J Circumpolar Health. 2008; 67(4): 335-48.

18. KJ Hamrick, J Smith. Potential future studies on the nutritional status among indigenous peoples in Alaska and the Russian Far East: preliminary assessment of the Social Transition in the North data set. Int J Circumpolar Health. 2004; Suppl 1: 43-8.

19. VW Chang, AE Hillier, NK Mehta. Neighborhood Racial Isolation, Disorder and Obesity. Soc Forces. 2009; 87(4): 2063-2092.

20. E Han, LM Powell. Consumption patterns of sugar-sweetened beverages in the United States. J Acad Nutr Diet. 2013; 113(1): 43-53.

21. SR Rolfes, K Pinna, EN Whitney, Understanding normal and clinical nutrition. 8th ed. 2009, Belmont, CA: Wadsworth/Cengage Learning.

22. SA Jebb, MS Moore. Contribution of a sedentary lifestyle and inactivity to the etiology of overweight and obesity: current evidence and research issues. Med Sci Sports Exerc. 1999; 31(11 Suppl): S534-41.

23. M Wei, JB Kampert, CE Barlow, MZ Nichaman, LW Gibbons, RS Paffenbarger, Jr. et al. Relationship between low cardiorespiratory fitness and mortality in normal-weight, overweight, and obese men. JAMA. 1999; 282(16): 1547-53. 